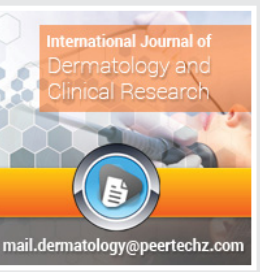

\title{
International Journal of Dermatology and Clinical Research
}

\section{Subhashini Mohan*}

Assistant professor of Dermatology, ESIC Medical college \& PGIMSR, KK Nagar, Chennai, Tamil Nadu, India

Dates: Received: 23 November, 2017; Accepted: 11 December, 2017; Published: 12 December, 2017

*Corresponding author: Subhashini Mohan, M.D., Assistant professor of Dermatology, ESIC Medical College \& PGIMSR, KK Nagar, Chennai, Tamil Nadu, India, Tel: +91 9940051361;

E-mail: drsubhashinimohan@gmail.com

Keywords: Mucocutaneous candidiasis; Superficial fungal infection; C.albicans

https://www.peertechz.com
Research Article

\section{A Study on clinical patterns of mucocutaneous candidiasis in immunosuppressed patients}

\section{Abstract}

Background: Candidasis is the most common superficial fungal infection in immunocompromised patients. With the advent of wide spectrum of immunosuppressive drug and increase in HIV patients, there is a change in the epidemiology and clinical presentation of mucocutaneous candidiasis.

Aim and Objective: This study has been designed to study epidemiology and the common clinical patterns of mucocutaneous candidiasis in immunosuppressed patients.

Materials and methods: A cross sectional study on epidemiology and clinical patterns of mucocutaneous candidiasis among 100 immunosuppressed patients of all age groups attending Dermatology OPD in a tertiary care center.

Results: Maximum number of patients were in third and fourth decade. Females were more frequently (73\%) affected than males (27\%). Type 2 diabetes was the most common cause of immunosuppression followed by steroid intake (20\%), cancer patients (10\%) and HIV (5\%). Oral candidiasis was the frequently observed clinical pattern (48\%) followed by vulvovaginal candidiasis $(45 \%)$, intertriginous lesions on the fingers $(2 \%)$, toes $(2 \%)$, and neck ( $1 \%)$. Balanoposthitis was observed in $2 \%$ of patients.

Limitation: small sample size.

Conclusion: Diabetes was the common cause of immunosuppression. Oral candidiasis was the common clinical pattern observed among them.

\section{Introduction}

Candida is a normal commensal in the oral cavity, gastrointestinal tract and the reproductive system. Patients with defective cell mediated immunity develop only mucocutaneous disease whereas dysfunction of neutrophils leads to systemic involvement. The clinical spectrum of candidiasis is extremely varied, ranging from acute, subacute, chronic and episodic [1,2]. Involvement may be localized to skin and mucosa or it may be systemic as in septicemia, endocarditis and meningitis. The pathologic response evoked is diverse and vary from irritation and inflammation to chronic and acute granulomatous response [2,3].

\section{Materials and Methods}

The study was conducted among patients attending the OPD, Mycology section of the Department of Dermatology in a tertiary care centre in India. Immunosuppressed individuals of all age groups were included in the study. A total of 100 randomly selected immunosuppressed patients with symptoms and signs of mucocutaneous candidiasis were included in the study. Patients who were on immunosuppressive drugs and various systemic diseases were included in the study. Patients who were on systemic antifungals for more than 4 weeks and topical antifungals for more than 2 weeks were excluded from the study. Specimens from mucosal and skin scrapings were examined in $10 \% \mathrm{KOH}$ for the presence of spores, hyphae and pseudohyphae. Inoculation was done in Sabouraud's dextrose agar and observed for growth of candida which appeared as cream colored smooth colonies with yeasty odor (Figure 1).

\section{Results}

We observed in our cohort a mean age of 41.5 years (age range 1 month-70 years). Age wise distribution is shown in table 1 . There was a female predominance with $73 \% \quad(n=100)$ and males were $27 \%$ (M:F ratio $1: 2.7$ ). Maximum number of females were in the age group of 31-40yrs and maximum number of males were in the age group of $41-50$ yrs. Of the 
100 immunosuppressed patients, type 2 diabetes was the most common cause of immunosuppression. $20 \%$ were on long term steroids for pemphigus vulgaris, bullous pemphigoid, Systemic lupus erythematoses, multicentric reticulohistiocytosis, pustular psoriasis and post renal transplant state. Two of them had chronic renal failure, $10 \%$ were on chemotherapeutic drugs and 5\% were HIV patients. All diabetic patients had their random blood sugar level in the range of $200-290 \mathrm{mg} /$ dl. The diabetic status of $50 \%$ of patients were on steroids induced. Most common clinical pattern observed was oral candidiasis $(48 \%)$ followed by vulvovaginal candidiasis $(45 \%)$. Intertriginous lesions in various sites like finger webspaces $(2 \%)$, toe webspaces $(2 \%)$ and neck $(1 \%)$. Balanoposthitis was found in $2 \%$ of the patients. Among the oral candidiasis patients, pseudomembranous pattern was the most common type in 20 patients followed by angular chelitis (perleche) in 15 patients, acute erythematous type in 8 patients [Figures 2,3 ]. A single patient with multicentric reticulohistocytosis who was on prolonged steroids initially presented with acute erythematous type of oral candidiasis and subsequently developed esophageal candidiasis. Acquired immunodeficiency disorder was found in 3 patients of which 2 patients had pseudomembranous type and one patient had perleche. Balanoposthitis and intertriginous lesions were exclusively found in type 2 diabetes patients [Figures 4,5] . All cancer patients on chemotherapy developed oral candidiasis. Among the 10 cancer patients 5 had leukemia, other 3 had carcionoma breast and one had carcinoma cheek.

\section{Discussion}

Candidiasis can affect all age groups. Immunosuppressed patients developed candidiasis more than theimmunocompetent

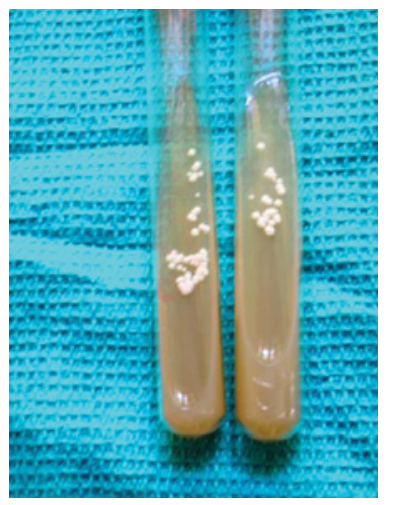

Figure 1: Creamy white colonies in Sabouraud's dextrose agar.

Table 1: Age wise distribution.

\begin{tabular}{|c|c|c|c|}
\hline Age & \multicolumn{2}{|c|}{ No of cases } & Total no of cases \\
\hline & Males & Females & \\
\hline $0-10$ & 1 & 1 & 2 \\
\hline $11-20$ & 3 & 0 & 3 \\
\hline $21-30$ & 3 & 16 & 19 \\
\hline $31-40$ & 2 & 22 & 24 \\
\hline $41-50$ & 11 & 14 & 25 \\
\hline $51-60$ & 5 & 9 & 14 \\
\hline $61-70$ & 2 & 11 & 13 \\
\hline
\end{tabular}

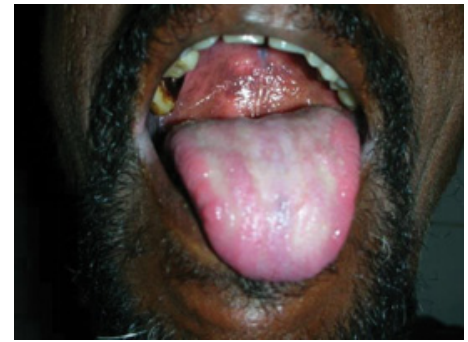

Figure 2: Pseudomembranous type of oral candidiasis.

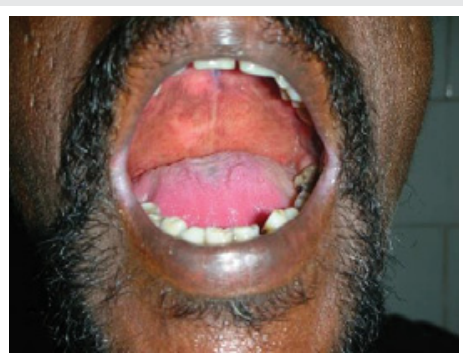

Figure 3: Angular chelitis.

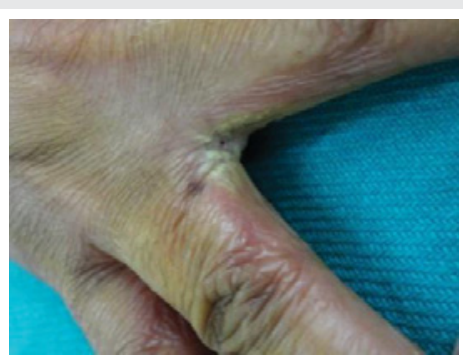

Figure 4: Intertrigo webspace.

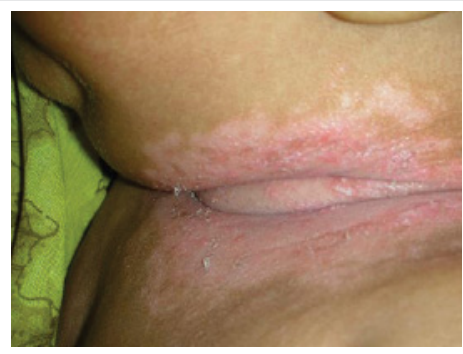

Figure 5: Intertrigo neck

individuals $[4,5]$. Safia et al., Reeding et al., proposed diabetes to be the predisposing factor for various fungal infections especially Candida spp $[6,7]$.

Oral candidiasis has been observed the most common manifestation of mucocandidiasis in this study [3,8]. All patients with oral candidiasis had type II diabetes and their blood sugar levels were between 200-290 mg/dl. Tapper Jones et al, Aly et al and Abu Elteen et al reported the prevalence of yeast carriage in diabetic individual to reach upto 54\% [9-12]. The relationship between the blood glucose level and carriage rate of Candida is controversial. Hill et al proposed that long duration of diabetes rather than diabetes by itself puts the patient at risk of oral candidiasis [13]. Gray et al proposed that there is no correlation between glycemic level and the Candida 
carriage rate [14]. Yet another study by Lamey et al showed the lack of association between HbA1c or blood glucose level and the Candida carriage rate [15]. Similar reports were also given by Kumar et al who stated that glycemic control and antidiabetic drugs have no correlation with the Candida carriage [16]. Oral candidiasis in pemphigus patients occurred as a complication of steroids. Pemphigus was shown to be associated with oral candidiasis in $24 \%$ in a study by Shaheen et al. [3]. All three HIV patients with oral candidiasis had their CD4 counts were between 374-400 cells $/ \mathrm{mm} 3$. Bodhade et al and Campo et al proposed that oral manifestations were common in HIV patients with CD4 counts less than 200 cells $/ \mathrm{mm}^{3}$ [17-19]. The presence of oral candidiasis in HIV patients in this study could be due to other contributing factors like poor oral hygiene and the prolonged use of antibiotics for prevention of opportunistic infection $[20,21]$. The number of patients in this study is small to establish a correlation with the CD4 count and the severity of oral candidiasis. Similar to our study leukemic patients developed candidiasis more frequently than other carcinoma patients. All patients were treated with topical and systemic antifungal drugs.

In summary, with increasing use of immunosuppressive agents and higher incidence of cancer candidiasis has become common fungal infection. Moreover it has increased the fatalities among bone marrow recipients.

\section{References}

1. Burns, Stephen Breathnach, Neil Cox, Christopher Griffiths (2010) Rook's Textbook of Dermatology; Eighth edition; 31.56-31.63. Link: https://goo.gl/m2SHzl

2. Chander J (1996) A Textbook of Medical mycology $22^{\text {nd }}$. 131-140.

3. Shaheen MA, Taha M (2006) Species identification of candida isolates from oral lesions of hospitalized and non hospitalized patients with oral candidiasis. Egyptian dermatology online journal 2: 1-13. Link: https://goo.gl/7WXtDs

4. Dreizen S, Keating MJ, Beran M (1992) Orofacial fungal infection. Nine pathogens that may invade during chemotherapy. Postgrad Med 91: 349350. Link: https://goo.gl/aP2djo

5. Hawkins C, Amstrong D (1984) Fungal infection in the immunocompromised host clinic. Clin Haematol13: 599-630. Link: https://goo.gl/W4oE4W

6. Safia A, AL-Atlas, Soliman O Amro (2010) Candidal colonization, strain diversity and antifungal susceptibility among adult diabetic patients; Ann Saudi Med 30: 101-108. Link: https://goo.gl/TUFxQK

7. Redding SW, Zeller RC, Kirk Patrick WR, McAtee RK, Caceres MA, et al. (1993) Epidemiology of orophrangeal candida colonization and infection in patients receiving radiation for head and neck cancer. J Clinc microbial 37: 38963900. Link: https://goo.gl/EQpZ3e
8. Bart chernow (1992) Immunosuppressive therapy of transplant recipients pharmacologic approach to critically ill patients.Ch 62 III edition. Williams and Wilkins Edn 1052-58

9. Zaremba ML, Daniluk T, Rokiewicz D, Cylwik-Rokicka D, Kiero Tokajuk G, et al. (2006) Incidence rate of candida species in oral cavity in the middle aged and elderly. Advances in Medical Sciences 51 Suppl 1: 233-236. Link: https://goo.gl/DK74jT

10. Tapper -Jones LM, Aldred MJ, Walker DM, T M Hayes (1981) Candidal infections and populations of candida albicans in mouths of diabetics. $J$ Clinc pathol 34: 706-711. Link: https://goo.gl/JGQ4mA

11. Aly FZ, Blackwell CC, Mackenzie DAC, Weir DM (1995) Identification of ora yeast isolates from individuals with diabetes mellitus. Mycoses 38: 107-110. Link: https://goo.gl/xHoNFF

12. Abu-Elteen $\mathrm{KH}$, Abu-Alteen RM (1998) The prevalence of Candida albicans population in the mouth of complete denture wearers. New Microbiol 21: 41 48. Link: https://goo.gl/pN3V1D

13. LV Hill, MH Tan, LH Perieira, JA Embil (1989) Association of Oral Candidiasis with diabetic control. J clincpathol 42: 502-505. Link: https://goo.gl/eikYU8

14. Gray A, Barthodomeu DMP, Brad Rodu DPS, David Bell MD (1987) Oral candidiasis in patients with diabetes mellitus: A thorough analysis. Diabetes Care 10: 607-612. Link: https://goo.gl/JnuGb2

15. Lamey PJ, Darwazah A, Fischer BM, Samaranayake LP, Macfarlane TW, et al (1988) Secertor status, candida carriage and candida infection in patients with diabetes mellitus. J Oral Pathol 17: 354-357. Link: https://goo.gl/fbx178

16. Kumar BV, Padshetty NS, Bai KY, Rao MS (2005) Prevalence of Candida in the oral cavity of diabetic subjects. J Assoc physician India 53: 599-602. Link: https://goo.gl/uRcVru

17. Ashish S. Bodhade, Sindhu M. Ganvir and Vinay K. Hazarey (2011) Oral manifestations of HIV infection and their correlation with CD4 count. J Oral Sci 53: 203-211. Link: https://goo.gl/XijVmx

18. Haylen González Gravina , Evelyn González de Morán, Olga Zambrano, María Lozano Chourio, Sofía Rodríguez de Valero, et al. (2007) Oral Candidiasis in children and adolescents with cancer. Identification of Candida spp. Med Oral Patol Oral Cir Bucal 12: E419-E423. Link: https://goo.gl/ThiKfC

19. Sardi JC, Scorzoni L, Bernadi T, Fusco -Almedia AM, Mendes Giannini MJ (2013) candida species: current epidemiology, pathogenicity, biofilm formation, natural antifungal products and new therapeutic options. J Med Microbiol 62: 10-24. Link: https://goo.gl/JtNgG4

20. Lyon JP, Moreira LM, Cardoso MAG, Saade J, Resende MA (2008) Antifungal suscepitibility profile of candida spp. oral isolates obtained from denture wearers. Braz J Microbiol 39: 668-672. Link: https://goo.gl/ZyWr2P

21. Aoun G, Berberi A (2017) Prevalence of Chronic Erythematous Candidiasis in Lebanese Denture Wearers: a Clinico-microbiological Study. Mater Sociomed 29: 26-29. Link: https://goo.gl/wuTyNA 